
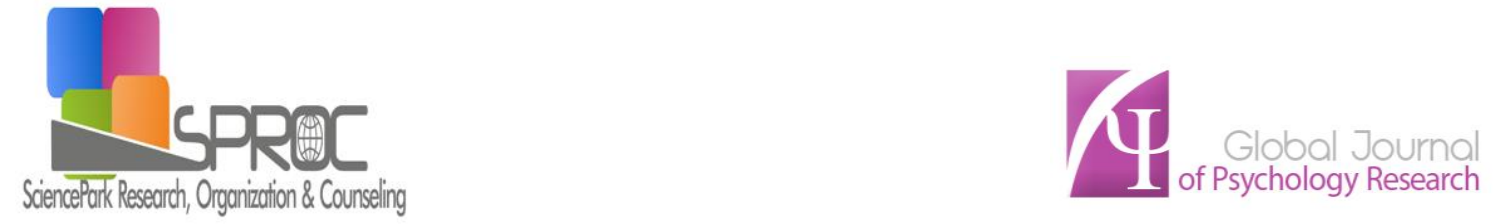

http://sproc.org/ojs/index.php/gipr

\title{
Means of psychomotor and cognitive recovery for children with autism spectrum disorder
}

Paul Ichim * Iuliana Barna, Mircea Dragu,

Suggested Citation:

Global Journal of Psychology Research. 5

Abstract

Paul Ichim,

E-mail address 
Global Journal of Psychology Research. 5

\section{Introduction}

\subsection{Diagnosis aspects}

$\bullet$

$\bullet$

$$
\text { - }
$$
$\cdot$

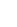

$\cdot$

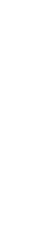

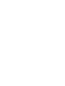


Global Journal of Psychology Research. 5

。

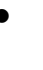

.

•

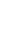

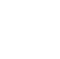

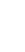

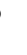

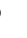

1.2. Multisystemic therapy in water 
1.3. MT approach as therapy

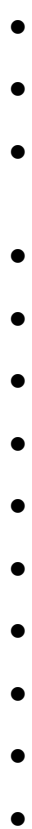

2. The importance of the multisystemic approach 
Global Journal of Psychology Research. 5

-

2.1. The importance of the aquatic environment 
Global Journal of Psychology Research. 5

\section{Conclusions}

\section{References}

